\title{
Pseudomonas fluorescens alters epithelial permeability and translocates across Caco-2/TC7 intestinal cells
}

\author{
Amar Madi ${ }^{1}$, Pascal Svinareff², Nicole Orange 1 , Marc GJ Feuilloley ${ }^{1}$, Nathalie Connil ${ }^{1 *}$
}

\begin{abstract}
Background: Pseudomonas fluorescens has long been considered as a psychrotrophic microorganism. Recently, we have shown that clinical strains of $P$. fluorescens (biovar 1 ) are able to adapt at a growth temperature of $37^{\circ} \mathrm{C}$ or above and induce a specific inflammatory response. Interestingly, a highly specific antigen of $P$. fluorescens, 12 , is detected in the serum of patients with Crohn's disease but the possible role of this bacterium in the disease has not yet been explored. In the present study, we examined the ability of a psychrotrophic and a clinical strain of P. fluorescens to modulate the permeability of a Caco-2/TC7 intestinal epithelial model, reorganize the actin cytoskeleton, invade the target cells and translocate across the epithelium. The behaviour of these two strains was compared to that of the well known opportunistic pathogen P. aeruginosa PAO1.

Results: Both strains of $P$. fluorescens were found to decrease the transepithelial resistance (TER) of Caco-2/TC7 differentiated monolayers. This was associated with an increase in paracellular permeability and F-actin microfilaments rearrangements. Moreover, the invasion and translocation tests demonstrated that the two strains used in this study can invade and translocate across the differentiated Caco-2/TC7 cell monolayers.

Conclusions: The present work shows for the first time, that $P$. fluorescens is able to alter the intestinal epithelial barrier function by disorganizing the F-actin microfilament network. Moreover, we reveal that independently of their origins, the two $P$. fluorescens strains can translocate across differentiated Caco-2/TC7 cell monolayers by using the transcellular pathway. These findings could, at least in part, explain the presence of the $P$. fluorescens specific 12 antigen in the serum of patients with Crohn's disease.
\end{abstract}

\section{Background}

Pseudomonas fluorescens has long been considered as a psychrotrophic microorganism, unable to grow at temperatures above $32^{\circ} \mathrm{C}$. Recently, we have shown that clinical strains of $P$. fluorescens (biovar 1) have been able to adapt at a growth temperature of $37^{\circ} \mathrm{C}$ or above [1]. This event appears relatively frequently and can lead to strains of increased virulence, in the range of the well known opportunistic pathogen Pseudomonas aeruginosa. Some of these clinical strains of $P$. fluorescens have a high hemolytic activity [2] presumably associated with type III or VI secretion systems and were shown to induce cytotoxic and proinflammatory responses on epithelial

\footnotetext{
* Correspondence: nathalie.connil@univ-rouen.fr

'LMDF-SME, Laboratory of Cold Microbiology-Signals and Microenvironment, UPRES EA 4312, 55 rue Saint Germain, 27000 Evreux, France Full list of author information is available at the end of the article
}

intestinal cells [3]. These observations and the incidence of declared nosocomial infections due to this germ [4] have changed the vision of the potential risk associated with $P$. fluorescens. This gram-negative bacterium is widespread in the environment where it is even more frequent than $P$. aeruginosa and has a remarkable fitness potential [5]. P. fluorescens is found in many ecological niches including soil and water but also in refrigerated food products where its psychrotrophic character gives it the possibility to grow in the relative absence of competitors [6].

$P$. fluorescens can also be found as a low level commensal of the human digestive tract [7]. Interestingly, a highly specific antigen of $P$. fluorescens, designated as I2, was detected in the serum of $54 \%$ of the patients suffering from ileal Crohn's disease (CD) [8] and a correlation between the severity of the pathology and the level of the circulating I2 antigen has been demonstrated [9].
C Biomed Central 
A relation between exposure to psychrotrophic germs and $C D$ is suggested by the parallel emergence and rise of the pathology in western countries and the widespread use of refrigerated food [10]. Although CD, as other chronic inflammatory bowel diseases, is typically a multifactorial pathology, these data underline the interest of better understanding of the possible interactions between $P$. fluorescens and the intestinal epithelium.

Bacterial pathogens can cause exacerbations or relapse of ulcerative colitis and CD. A healthy intestinal epithelium acts as a barrier between foreign antigens and the underlying lymphoid tissue. Many pathogens have developed strategies to circumvent the barrier function of an intact epithelium. These include inflammatory induction, physical disruption of the barrier and crossing the epithelial cell monolayer. The barrier function is maintained by tight junctions, which are dynamic cell-cell adhesions that form a continuous seal around the cells and control the permeability of solutes and fluids diffusing through the paracellular pathway [11]. Tight junctions are formed by transmembrane proteins, such as claudins and occludin, and cytosolic proteins recruited to the apicolateral membrane, including zonula occludens proteins, cingulin and 7 H6 [12,13]. Cytoskeletal components are anchored to tight junction structures through the cytosolic proteins, forming a perijunctional acto-myosin ring which gives the junction architectural support. These components of the cytoskeleton may also be involved in shuttling signalling molecules to and from the junctions $[14,15]$. Consequently, tight junctions can be disrupted by rearrangement and contraction of the perijunctional acto-myosin ring and this could lead to variations in transepithelial resistance (TER). Alteration of the epithelial barrier function by pathogens can be associated with translocation of the microorganisms across the monolayer. Such mechanisms are used by many enteropathogens, like Salmonella, Yersinia, Shigella or Listeria, to disseminate within the host. Three translocation mechanisms are relevant to the intestinal epithelium: (i) exploitation of $M$ cells, specialized intestinal epithelial cells which transport luminal antigens across the epithelial barrier to underlying lymphoid tissue; [16] transcellular translocation or trancytosis, in which pathogens invade epithelial cells, migrate across the cytoplasm and egress from the opposite surface; and (iii) paracellular translocation or paracytosis, in which bacteria travel extracellulary through tight junctions between adjacent epithelial cells. Translocation across intestinal epithelial cells barriers via all these three mechanisms has been reported for Campylobacter jejuni which in turn promotes the translocation of other commensal bacteria $[17,18]$.

We have recently shown that $P$. fluorescens can adhere to intestinal epithelial cells, has cytotoxic activity and induces a specific inflammatory response [3], but the ability of this bacterium to alter the intestinal epithelial barrier function or to translocate across this epithelium has not yet been studied until now. In the present study, we examined the ability of a psychrotrophic and a clinical strain of $P$. fluorescens to modulate the permeability of a Caco-2/TC7 intestinal epithelial model, reorganize the actin cytoskeleton, translocate across the epithelium and invade the target cells. The behaviour of these two strains was compared to that of the well known opportunistic pathogen $P$. aeruginosa PAO1.

\section{Methods}

\section{Bacterial strains}

P. fluorescens MFN1032 (biovar I) was collected in a hospital of Haute-Normandie (France). It was characterized by polyphasic identification, $16 \mathrm{~S}$ RNA sequencing and siderotyping [1]. P. fluorescens MF37 is a spontaneous rifampicin-resistant mutant of the strain MF0 (biovar V), originally identified in crude milk [19]. P. aeruginosa PAO1 was obtained from an international collection. All the strains were cultivated in ordinary nutrient broth (Merk, Darmstadt, Germany), at $28^{\circ} \mathrm{C}$ for the two strains of $P$. fluorescens or $37^{\circ} \mathrm{C}$ for P. aeruginosa PAO1.

\section{Cell line and culture}

The Caco-2/TC7 clone established from the parental human enterocytes-like Caco-2 cell line [20] was used between passages 25 and 35. Cells were routinely grown in Dulbecco's Modified Eagle's Medium (DMEM, invitrogen) supplemented with $15 \%$ heat-inactived fetal calf serum, $2 \mathrm{mM}$ of L-glutamine, $100 \mathrm{U} / \mathrm{ml}$ each of penicillin and streptomycin and 1\% non essential amino acids. For experimental assays, the cells were seeded at a density of approximately $10^{5}$ cells $/ \mathrm{cm}^{2}$ in 24-well tissue culture plates or on inserts $(6.4 \mathrm{~mm}$ diameter, $3 \mu \mathrm{m}$ pore size, Falcon) which allow epithelial differentiation between apical and basolateral compartments. The cells were cultured at $37^{\circ} \mathrm{C}$ in $5 \% \mathrm{CO}_{2}-95 \%$ air atmosphere and the medium was changed daily. Caco-2/TC7 cells grown in 24-well tissue culture plates were incubated to early confluence (undifferentiated cells). Caco-2/TC7 cells grown on inserts were used at 21 days post-confluence (fully differentiated cells).

\section{Cell infection}

Bacteria in early stationary phase (grown overnight) were harvested by centrifugation $\left(5000 \mathrm{~g}, 5 \mathrm{~min}, 20^{\circ} \mathrm{C}\right)$ and resuspended at a density of $10^{8}$ colony forming unit $(\mathrm{CFU}) / \mathrm{ml}$ in cell culture medium without serum and antibiotics. Caco-2/TC7 grown on 24-well culture plates (undifferentiated cells) or inserts (fully differentiated cells) were washed twice with fresh cell culture medium and the bacterial suspensions were applied to the surface or to the apical compartments at a concentration of $10^{8} \mathrm{CFU} / \mathrm{cm}^{2}$. Infected cells were then incubated at 
$37^{\circ} \mathrm{C}$ in $5 \% \mathrm{CO}_{2}-95 \%$ air during $24 \mathrm{~h}$ for permeability, 3 or $6 \mathrm{~h}$ for translocation and $4 \mathrm{~h}$ for invasion assays. Each assay was conducted in triplicate in independent experiments (successive passages of Caco-2/TC7 cells).

\section{Transepithelial resistance measurements}

The transepithelial resistance (TER) of differentiated Caco-2/TC7 monolayers was studied during $24 \mathrm{~h}$, using the Millicell Electrical Resistance System (Millipore Corp, Bedford, MA). TER values are expressed as percentages of the pre-infection level of the TER (baseline) measured for each individual cell monolayer in the inserts.

\section{Cytotoxicity assay}

At the end of infection, the supernatants from Caco-2/ TC7 monolayers were collected and the concentration of lactate dehydrogenase ( $\mathrm{LDH}$ ), a cytoplasmic enzyme released upon cell death, was determined using an enzymatic assay (Cytotox 96 Promega, Charbonnieres, France) as previously described [3].

\section{Quantification of paracellular flux}

Paracellular permeability was quantified using the fluorescein isothiocyanate dextran tracer $4 \mathrm{kDa}$ (FD-4). One hour before the end of infection, $1 \mathrm{mg} / \mathrm{ml}$ of FD- 4 was added to the apical side of differentiated Caco-2/TC7 monolayers and the amount of FD- 4 translocated to the basolateral medium was then measured by fluorimetry using a TD700 fluorometer (Turner Designs) (485 nm excitation and $528 \mathrm{~nm}$ emission wavelengths). The results are expressed as a percentage of apical dextran that crossed the insert membrane per $\mathrm{cm}^{2}$ and per hour as described by Lynch et al [21].

\section{Actin visualisation}

At the end of infection, apical F-actin cytoskeleton was visualized. Briefly, differentiated Caco-2/TC7 monolayers were washed with phosphate-buffered saline (PBS), fixed for $10 \mathrm{~min}$ in $3.7 \%$ paraformaldehyde and permeabilized for 5 min with $0.1 \%$ Triton X100 at room temperature. The cells were incubated with $1 \%$ bovine serum albumine in PBS for $10 \mathrm{~min}$. F-actin was stained by incubation with Alexa-488 phallö̈dine (1 U/insert) for $45 \mathrm{~min}$ at room temperature. Following three washes in PBS, cell monolayers were excised from the filter supports, mounted on slides using Fluoromount/Plus mounting medium (Diagnostic BioSystems) and examined using a confocal laser scanning microscope (Zeiss, LSM710).

\section{Bacterial translocation}

After 3 and $6 \mathrm{~h}$ of bacterial infection, aliquots of $100 \mu \mathrm{l}$ of the basolateral compartment were collected and the number of bacteria that crossed the epithelial monolayers was determined by serial dilution and plating onto nutrient agar. P. fluorescens and P. aeruginosa are aerobic bacteria which require free access to oxygen for a rapid multiplication. Indeed, control studies showed that in our experimental conditions, the growth of $P$. fluorescens and P. aeruginosa in the basolateral compartment of the inserts was negligible. This observation allows to consider that the bacterial population measured in the basolateral compartment is actually corresponding to bacteria that crossed the epithelial barrier.

\section{Bacterial invasion assay}

After $4 \mathrm{~h}$ of infection, Caco-2/TC7 monolayers grown in 24-well culture plates or inserts were washed with PBS. Adherent bacteria were killed by incubation for $1 \mathrm{~h}$ with $300 \mu \mathrm{g} / \mathrm{ml}$ gentamycin, an antibiotic that does not cross the cytoplasmic membrane of eukaryotic cells and then only kills bacteria not internalized in cells. Caco-2/TC7 monolayers were washed 3 times with PBS to remove the antibiotic and dead bacteria and were lysed by incubation for 15 min with $0.1 \%$ Triton X100 to release the intracellular bacteria. The lysates were then plated onto nutrient agar to determine the number of internalized bacteria.

\section{Statistical analysis}

All experiments were conducted independently at least three times. The results are expressed as means \pm standard error of the mean [22] and statistical significance were performed by ANOVA with Bonferroni post hoc test.

\section{Results}

\section{$P$. fluorescens can alter the epithelial barrier function}

The effect of P. fluorescens MF37, P. fluorescens MFN1032 and $P$. aeruginosa PAO1 infection on epithelial permeability was evaluated by measuring the TER across differentiated Caco-2/TC7 monolayers (Figure 1). TER values were measured at the onset of the experiment and at times 3, 6, 9 and $24 \mathrm{~h}$. Up to $9 \mathrm{~h}$ after the beginning of the experiment, the TER values of the monolayers exposed to P. fluorescens MF37, P. fluorescens MFN1032 and $P$. aeruginosa PAO1 remained unchanged. After $24 \mathrm{~h}$ of infection, the TER of the monolayers exposed to the two strains of $P$. fluorescens were significantly decreased $(-20.3 \pm 3.9 \%$ for MF37 and $-18.3 \pm 3.1 \%$ for MFN1032). P. aeruginosa led to a deeper decrease of the TER value $(55.8 \pm 5.3 \%)$. The fall in TER can not be attributed to damages provoked by acidification of the medium since the $\mathrm{pH}$ of the medium remained constant over the studies.

\section{The decrease of TER is associated with an increase in paracellular permeability}

The observed decrease in TER can have three causes: (i) an increase of paracellular permeability, [16] cell lysis 


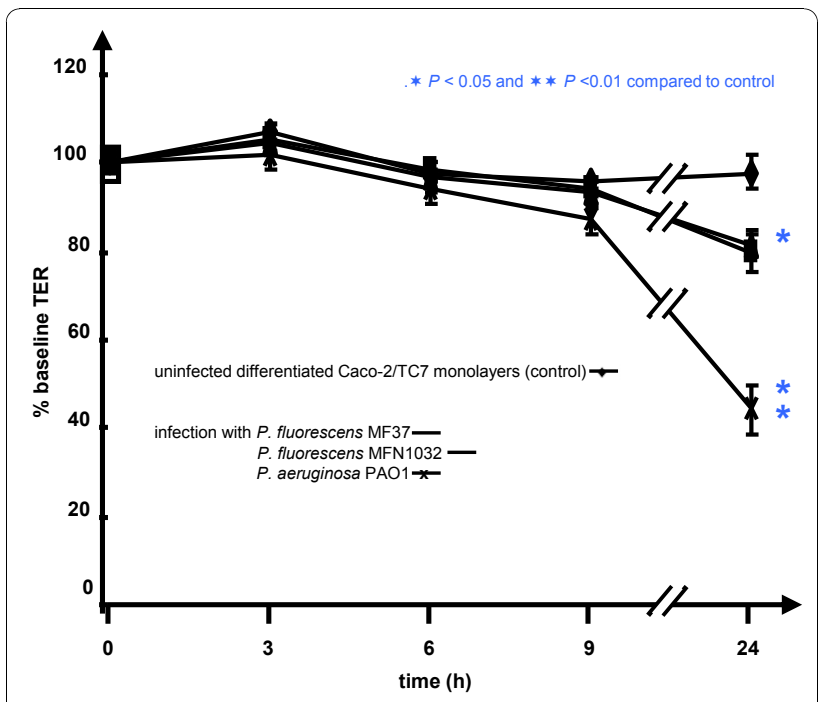

Figure 1 Pseudomonas fluorescens MF37, P. fluorescens MFN1032 and $P$. aeruginosa PAO1 decrease the transepithelial resistance of Caco-2/TC7 cell monolayers: TER measurements after infection with $P$. fluorescens MF37, P. fluorescens MFN1032 and P. aeruginosa PAO1 compared to uninfected differentiated Caco-2/TC7 monolayers (control). The data are expressed as percentage of the initial TER measured across the monolayer at the onset of the experiment. Results are the means values \pm standard errors of the means (SEM) for at least three independent experiments.

and epithelium disorganization or (iii) variations of ion fluxes across an intact monolayer. To distinguish between these possibilities, cell lysis was estimated by an assay of LDH released upon cell death after $24 \mathrm{~h}$ of infection and the paracellular permeability was quantified by measuring the apical to basolateral flux using $4 \mathrm{kDa}$ dextran tracer (FD-4). Only P. aeruginosa PAO1 had a marginal cytotoxic effect on differentiated Caco-2/TC7 cell monolayers after $24 \mathrm{~h}$ of incubation (data not shown). In contrast, the three tested bacteria provoked a significant increase in the paracellular permeability after $24 \mathrm{~h}$ of incubation (Figure 2). The paracellular permeability of control differentiated Caco-2/TC7 monolayers was low (3.2 $\pm 0.3 \%$ of apical FD4 crossing the epithelial barrier/ $\left.\mathrm{cm}^{2} / \mathrm{h}\right)$. P. aeruginosa PAO1 caused the greatest increase of paracellular permeability with $22.8 \pm 10.8 \%$ of apical FD-4 crossing the barrier $/ \mathrm{cm}^{2} / \mathrm{h}$. The effect of $P$. fluorescens MF37 and P. fluorescens MFN1032 was less pronounced but reached $10.6 \pm 4.1 \%$ and $7.4 \pm 1.2 \%$ FD -4 crossing $/ \mathrm{cm}^{2} / \mathrm{h}$, respectively.

\section{$P$. fluorescens induces apical F-actin filaments reorganization}

Because F-actin filaments in the apical poles of epithelial cells are intimately linked to and regulate tight junction functions, we looked at the effect of $P$. fluorescens MF37, $P$. fluorescens MFN1032 and P. aeruginosa PAO1 on the

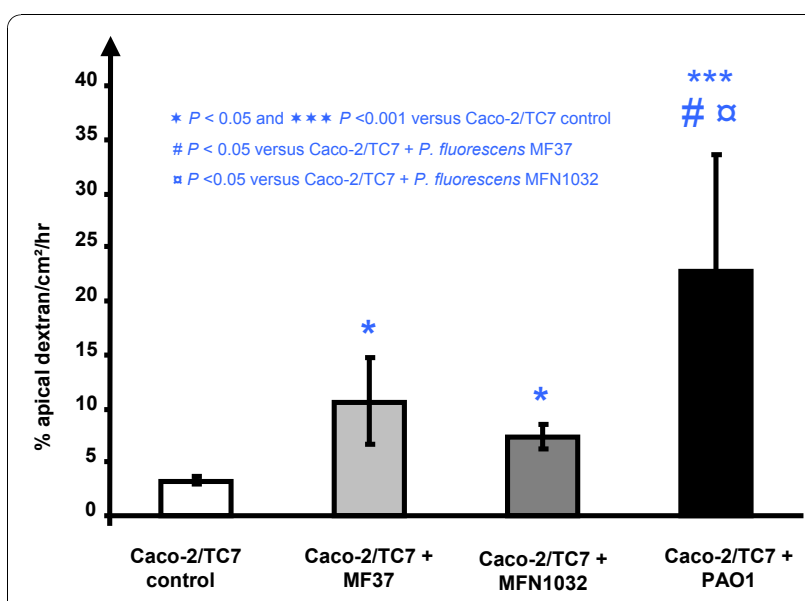

Figure 2 The TER decrease is accompanied by an increase in paracellular permeability. Apical-to-basolateral FD-4 flux in response to infection with $P$. fluorescens MF37, P. fluorescens MFN1032 and $P$. aeruginosa PAO1. The data are the percentages of apical FD-4 crossing the insert membrane per $\mathrm{cm}^{2}$ per hour and are the means values \pm SEM of at least three independent experiments.

organization of the sub-membrane microfilament network. As shown in Figure 3, incubation with bacteria induced a dramatic reorganization of apical epithelial F-actin. The staining pattern of untreated Caco-2/TC7 showed a continuous fine meshwork of microfilaments lining the cell border. In cells exposed for $24 \mathrm{~h}$ to the three bacterial strains, the normal organization of microfilaments was replaced by a diffused and loose network of F-actin fibers. Moreover, these changes were accompanied by the formation of dense clusters of apparently amorphous F-actin, particularly after treatment with the clinical strain $P$. fluorescens MFN1032 and with P. aeruginosa PAO1.

\section{P. fluorescens translocates across Caco-2/TC7 monolayers}

After apical infection of differentiated Caco-2/TC7 monolayers, bacterial strains were quantified in the basolateral medium at different times. After three hours of infection, bacteria were not detectable in the basolateral compartment. However, after $6 \mathrm{~h}$ of infection, $1.5 \pm 2.2 \times 10^{4}, 2.9$ $\pm 2.5 \times 10^{3}$ and $7.2 \pm 2.2 \times 10^{5} \mathrm{CFU} / \mathrm{ml}$ were detected with $P$. fluorescens MF37, $P$. fluorescens MFN1032 and $P$. aeruginosa PAO1, respectively (Figure 4). These values of bacterial translocation remain marginal compared to the size of the initial inoculum $\left(10^{8} \mathrm{CFU}\right)$. Nevertheless, if we consider that these results indicate that $1 / 1000$ to $1 / 10,000$ of Pseudomonas can cross the epithelium within $6 \mathrm{~h}$, these values may be highly significant in a situation of chronic exposure to these bacteria.

\section{P. fluorescens can translocate without disrupting Caco-2/TC7 cell monolayer integrity}

Bacterial translocation through the monolayer can result either from trans- or paracellular passage of the bacteria 


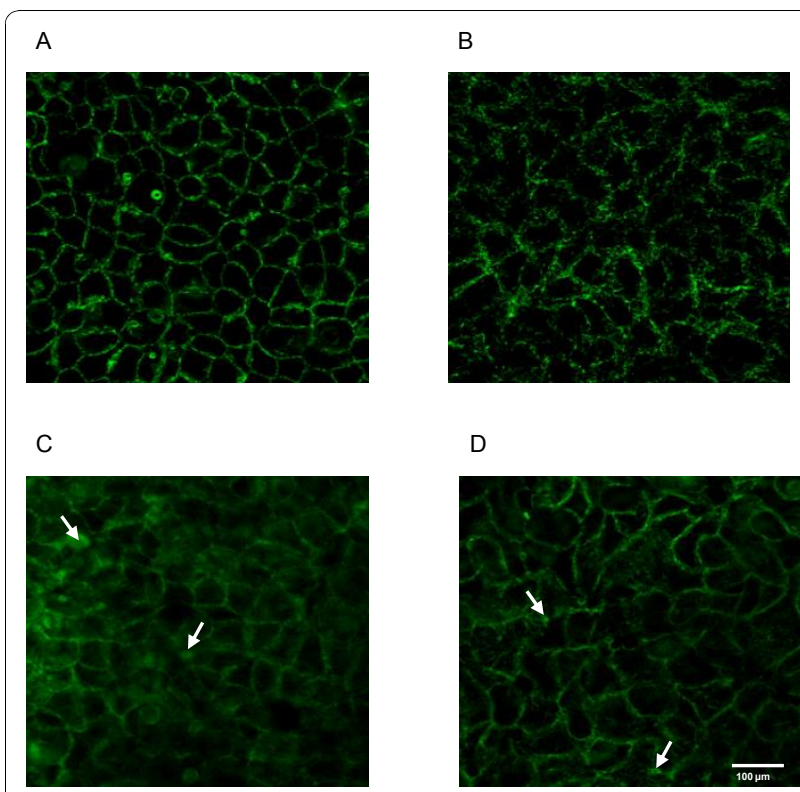

Figure 3 Pseudomonas fluorescens MF37, P. fluorescens MFN1032 and $P$. aeruginosa PAO1 cause disruption of the apical F-actin cytoskeleton. Fluorescent F-actin staining showing organized F-actin filaments lining the apical tight-junction system of control differentiated Caco-2/TC7 cell monolayer (A). In cell monolayers infected with P. fluorescens MF37 (B), P. fluorescens MFN1032 (C) and $P$. aeruginosa PAO1 (D) the sub-membrane microfilament network is loose. Clusters of amorphous actin can be observed, particularly after infection with P. fluorescens MFN1032 and $P$. aeruginosa PAO1 (arrows).

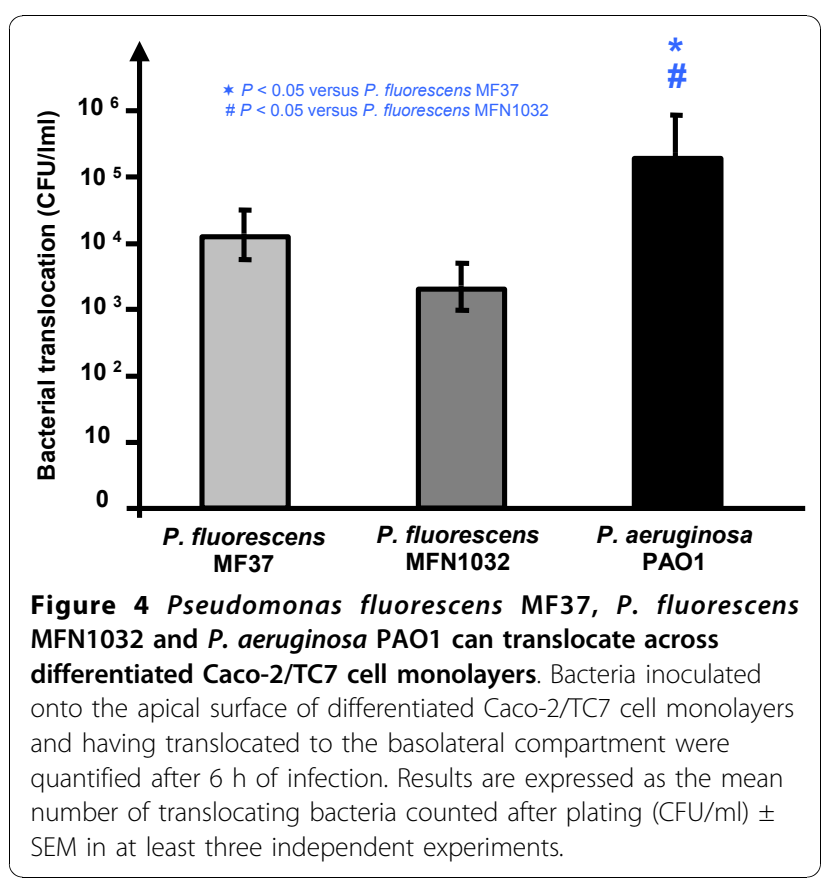

or more simply from gaps formed in the monolayer following the death of some epithelial cells. The TER was evaluated at different times and, as previously shown in Figure 1, this value remained identical for all tested bacteria between the onset of the experiment and $9 \mathrm{~h}$ of incubation. This absence of variation of TER indicates that the monolayer integrity was maintained at least $9 \mathrm{~h}$ after the infection. These results are in agreement with measures taken using FD- 4 between 0 and $9 \mathrm{~h}$ of incubation with bacteria that showed no significant variations of paracellular permeability during these short incubation periods (data not shown).

\section{$P$. fluorescens can be invasive in Caco-2/TC7 cells}

Since the differentiated Caco-2/TC7 monolayer remained intact and the paracellular permeability was unchanged at times when bacteria were actually recovered in the basolateral compartment, these results suggested that Pseudomonas are able to invade epithelial cells, migrate across the cytoplasm and egress at the level of the basal membrane. This possible transcellular translocation of Pseudomonas was investigated using the gentamicin exclusion test. The behaviour of bacteria was different in undifferentiated and differentiated cells. In undifferentiated Caco-2/TC7 cells, only $P$. aeruginosa PAO1 was invasive $\left(2.5 \times 10^{5} \mathrm{CFU} / \mathrm{ml}\right)$ whereas no P. fluorescens MF37, or P. fluorescens MFN1032 were detected in the intracellular compartment (Figure 5A). The situation was different in differentiated Caco-2/TC7 monolayers where the three bacterial strains had clearly an invasive behaviour with $0.9 \pm 0.2 \times 10^{5}, 2.6 \pm 0.2 \times$ $10^{5}$ and $0.6 \pm 0.3 \times 10^{5} \mathrm{CFU} / \mathrm{ml}$ detected in the intracellular compartment for P. fluorescens MF37, P. fluorescens MFN1032 and P. aeruginosa PAO1, respectively (Figure 5B). It is interesting to note that in the differentiated monolayer, the two strains of $P$. fluorescens were more invasive that $P$. aeruginosa PAO1, and the level of the clinical strain of $P$. fluorescens MFN1032 was more than 4 times that of the $P$. aeruginosa strain

\section{Discussion}

Precise regulation of intestinal epithelial tight junctions is crucial to maintain the barrier function between the luminal compartment and the interior medium. Numerous mucosal pathogens can modulate tight junctions and translocate across the epithelial barrier leading to established disease states. In this regard, our pioneer works $[23,24]$ and the recent studies demonstrating that $P$. fluorescens can clearly act as an opportunistic pathogen $[3,25]$ underscore the need to further characterize the virulence potential of this microorganism. In the present work, we studied the translocation and invasion potential of $P$. fluorescens on differentiated Caco-2/TC7 epithelial intestinal cell monolayers and the effect of the 


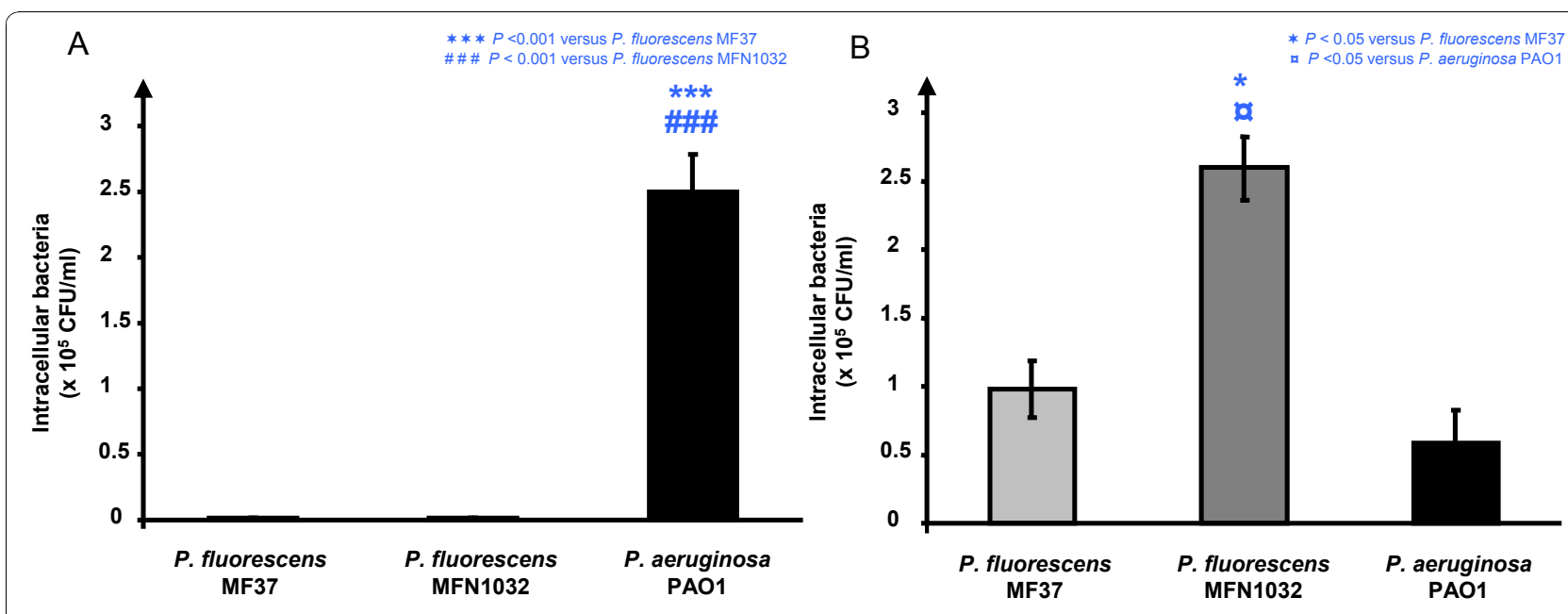

Figure 5 Pseudomonas fluorescens MF37, P. fluorescens MFN1032 and P. aeruginosa PAO1 can be invasive in Caco-2/TC7 cells. Undifferentiated (A) or differentiated (B) Caco-2/TC7 cells were infected for $4 \mathrm{~h}$ and intracellular bacteria were quantified by plating after gentamicin destruction of extracellular germs. Results are expressed as the mean number of bacteria (CFU/ml) \pm SEM recovered in the intracellular compartment in at least three independent experiments.

bacteria on paracellular permeability and tight junctions associated actin cytoskeleton. The behaviour of these bacteria was compared to that of the opportunistic pathogen P. aeruginosa PAO1.

We demonstrate that, independently of their maximal growth temperature, the two strains of $P$. fluorescens MF37 and MFN1032, respectively from environmental and clinical origin, can lead to a time-dependent decrease of the epithelial barrier function. This effect starts after $9 \mathrm{~h}$ of contact between the bacteria and the epithelial cells but is more pronounced at $24 \mathrm{~h}$ post-infection. This decrease of TER is lower than that induced by $P$. aeruginosa PAO1. This result is logical since it has been demonstrated that the $P$. aeruginosa quorum sensing factor N-(3 oxodecanoyl)-L-homoserine lactone can disrupt the epithelial barrier integrity of Caco-2 cells [26] whereas $P$. fluorescens is not known to produce $\mathrm{N}$-acyl homoserine lactones. The quorum sensing factors expressed by this species remain to be identified. Compared to some other bacteria such as Escherichia coli O157 which are known to cause a rapid decrease in TER [27], the decrease of TER observed after treatment with the two $P$. fluorescens strains presently studied was slow, suggesting that this effect on TER is mediated by synthesis of active molecules either by epithelial cells and/or bacteria. Indeed, P. fluorescens, and particularly a strain such as MFN1032, is known to produce exoenzymes but also cyclo-lipopeptides [28]. On the other hand, it is now obvious that many eukaryotic communication factors, including peptides locally produced by the intestinal epithelium, can enhance the virulence of Pseudomonas [29]. A decrease of TER can result either from an increase in paracellular permeability, local cell lysis in the monolayer or change in ion flux across the intact monolayer. To distinguish between these possibilities, LDH released by lysed cells was quantified and fluorescent markers of paracellular flux were used. We have previously shown that $P$. fluorescens MF37 and $P$. fluorescens MFN1032 can exert a cytotoxic effect on confluent undifferentiated epithelial intestinal cells [3]. Surprisingly, on fully differentiated Caco-2/TC7 cells cultivated on insert, no significant cytotoxicity was observed, even after $24 \mathrm{~h}$ of infection with these two strains. This indicates that the increase of TER is not due to direct toxic effects and cell lysis. Only infection with $P$. aeruginosa $\mathrm{PAO} 1$ provoked a modest lysis of fully differentiated Caco-2/TC7 cells explaining the higher effect of this strain on the TER values. It has been shown that, as the epithelial barrier differentiates and becomes highly polarized, it is more resistant to $P$. aeruginosa infection [30]. This could explain the rather low cytotoxicity of the three Pseudomonas species or strains presently studied in comparison with our previous results obtained on undifferentiated cells [3].

The integrity of the epithelial cell monolayer is maintained by intercellular junctional complexes composed of tight junctions, adherens junctions and desmosomes. The tight junctions are the most apical intercellular junctions. They form a continuous belt-like structure at the luminal end of intercellular space that regulates the paracellular flux [31]. Some bacterial pathogens can manipulate the apical-junctional complex and one of the principal strategies used by these microorganisms is to trigger actin cytoskeleton contraction [32]. In the present study, the confocal laser scanning microscope examination of apical F-actin revealed that $P$. fluorescens 
MF37, P. fluorescens MFN1032 and P. aeruginosa PAO1 induced a profound reorganization of the enterocyte actin cytoskeleton. This effect is very similar to that reported in cells exposed to Vibrio parahaemolyticus [21] or enteropathogenic E. coli [33]. These observations are in agreement with the results obtained by measurement of TER and FD-4 flux across the cell monolayer.

Our recent observations indicate that $P$. fluorescens induces the secretion of the proinflammatory cytokine interleukin (IL)-8 in epithelial intestinal cells [3]. IL-6, IL- $1 \beta$ and TNF- $\alpha$ secretion are also induced in human cultured A549 pulmonary cells by P. fluorescens [25]. Proinflammatory cytokines released in the gut can increase paracellular permeability by modulating tight junction protein expression and phosphorylation [34]. Moreover, modest inflammatory and metabolic stress are known to promote the translocation and transcytosis of commensal bacteria such as E. coli $\mathrm{C} 25$ across gut enterocytes [35]. Consequently, we investigated the ability of $P$. fluorescens MF37, P. fluorescens MFN1032 and $P$. aeruginosa PAO1 to translocate across the Caco-2/ TC7 cell monolayers. We found that although the translocation is limited compared to the initial inoculum, these bacteria were observed to readily translocate across Caco-2/TC7 monolayers after $6 \mathrm{~h}$ of infection. Most importantly, TER measurements and FD-4 flux indicate that at this time, the cell monolayer integrity was maintained in the presence of the translocating bacteria. Numerous mucosal bacteria, such as Salmonella typhymurium, translocate across the epithelial barrier and this translocation is associated with a complete loss of TER after $6 \mathrm{~h}$ [36]. Pathogen bacteria of the Pseudomonas genus are generally considered as extracellular microorganisms. However, these bacteria have been shown to have an invasive behaviour in specific eukaryotic cells such as corneal epithelial cells for $P$. aeruginosa [37] and cortical neurons for P. fluorescens [38]. Our results suggest that the translocation of Pseudomonas, through the cell monolayers, occurs after invasion of the differentiated cells. It is known that $S$. typhymurium and E. coli M12 are more invasive in immature undifferentiated than in differentiated Caco-2 cells [39]. In contrast, in our study the gentamicin exclusion test demonstrates that while $P$. aeruginosa $\mathrm{PAO} 1$ invade both polarized and non-polarized Caco-2/TC7 cells, $P$. fluorescens only invades the differentiated cells. As expected for a clinical strain, P. fluorescens MFN1032 had a higher invasive activity than its psychrotrophic and environmental counterpart P. fluorescens MF37. However, despite this higher invasion potential, the translocation level of $P$. fluorescens MFN1032 was similar to that of MF37. These observations can be explained by the fact that polarized epithelial cells are characterized by the presence of membrane proteins distributed to apical or basolateral surfaces, and these proteins may be absent or poorly expressed in undifferentiated epithelial cells. Then, bacteria may preferentially interact with these proteins, exhibiting affinity for either apical or basolateral surfaces, or for differentiated or undifferentiated epithelial cells [40].

\section{Conclusion}

Our results reveal that the psychrotrophic strain P. fluorescens MF37 and the clinical strain P. fluorescens MFN1032 have very similar effects on Caco-2/TC7 cells and can contribute to a decrease in the barrier effect of the intestinal epithelium. As these bacteria have a low cytotoxic activity, in these cells, they apparently disorganize intercellular junctions by acting on the F-actin microfilament network. Moreover, we have shown that independently of its origins and physiological variations, P. fluorescens can translocate across differentiated Caco-2/ TC7 cell monolayers by using the transcellular pathway. These findings could, at least in part, explain the presence of the P. fluorescens specific I2 antigen in the serum of patient with CD. Further studies of the effects of this bacterium on the expression and distribution of tight junction proteins of intestinal epithelial cells, may help to understand the molecular mechanism used by this bacterium to modulate the intestinal epithelial barrier function.

\section{Aknowledgments}

This study was supported by grants from the Conseil Général de l'Eure, the Communauté d'Agglomération d'Evreux and Europe. LMDF-SME is a member and supported by the world's leading center Cosmetic Valley. AM is a recipient of a doctoral fellowship from the Région Haute-Normandie and BioGalenys.

The authors wish to thank Christine Farmer for English reviewing of the manuscript.

\section{Author details}

'LMDF-SME, Laboratory of Cold Microbiology-Signals and Microenvironment, UPRES EA 4312, 55 rue Saint Germain, 27000 Evreux, France. ${ }^{2}$ BIOGALENYS, 9 Rue de Pacy, 27930 Miserey, France.

\section{Authors' contributions}

AM carried out most experiments and analyzed most of the data. NC wrote the manuscript and participated in the design of the study. PS and NO helped to draft the manuscript. MF participated in the design of the study and writing of the manuscript. All authors read and approved the final manuscript.

\section{Competing interests}

The authors declare that they have no competing interests.

Received: 8 October 2010 Accepted: 27 November 2010

Published: 27 November 2010

\section{References}

1. Chapalain A, Rossignol G, Lesouhaitier O, Merieau A, Gruffaz C, Guerillon J, Meyer JM, Orange N, Feuilloley MG: Comparative study of 7 fluorescent pseudomonad clinical isolates. Can J Microbiol 2008, 54(1):19-27.

2. Sperandio D, Rossignol G, Guerillon J, Connil N, Orange N, Feuilloley MG, Merieau A: Cell-associated hemolysis activity in the clinical strain of Pseudomonas fluorescens MFN1032. BMC Microbiol 2010, 10:124. 
3. Madi $A$, Lakhdari $O$, Blottière HM, Guyard-Nicodème $M$, Le Roux $K$ Groboillot A, Svinareff P, Doré J, Orange N, Feuilloley MG, Connil N: The clinical Pseudomonas fluorescens MFN1032 strain exerts a cytotoxic effect on epithelial intestinal cells and induces Interleukin-8 via the AP-1 signaling pathway. BMC Microbiol 2010, 10:215.

4. Farquhar MG, Palade GE: Junctional complexes in various epithelia. J Cell Biol 1963, 17:375-412.

5. McDonald MJ, Cooper TF, Beaumont HJ, Rainey PB: The distribution of fitness effects of new beneficial mutations in Pseudomonas fluorescens. Biol Lett .

6. Rajmohan S, Dodd CE, Waites WM: Enzymes from isolates of Pseudomonas fluorescens involved in food spoilage. J Appl Microbiol 2002, 93(2):205-213.

7. Wei B, Huang T, Dalwadi H, Sutton $\mathrm{CL}$, Bruckner D, Braun J: Pseudomonas fluorescens encodes the Crohn's disease-associated 12 sequence and Tcell superantigen. Infect Immun 2002, 70(12):6567-6575.

8. Sutton CL, Kim J, Yamane A, Dalwadi H, Wei B, Landers C, Targan SR, Braun J: Identification of a novel bacterial sequence associated with Crohn's disease. Gastroenterology 2000, 119(1):23-31.

9. Dalwadi H, Wei B, Kronenberg M, Sutton CL, Braun J: The Crohn's diseaseassociated bacterial protein 12 is a novel enteric $t$ cell superantigen. Immunity 2001, 15(1):149-158.

10. Hugot JP, Alberti C, Berrebi D, Bingen E, Cezard JP: Crohn's disease: the cold chain hypothesis. Lancet 2003, 362(9400):2012-2015.

11. Yap AS, Mullin JM, Stevenson BR: Molecular analyses of tight junction physiology: insights and paradoxes. J Membr Biol 1998, 163(3):159-167.

12. Baumgart DC, Dignass AU: Intestinal barrier function. Curr Opin Clin Nutr Metab Care 2002, 5(6):685-694.

13. Tsukita S, Furuse M, Itoh M: Structural and signalling molecules come together at tight junctions. Curr Opin Cell Biol 1999, 11(5):628-633.

14. Ma TY, Hollander D, Tran LT, Nguyen D, Hoa N, Bhalla D: Cytoskeletal regulation of Caco-2 intestinal monolayer paracellular permeability. J Cell Physiol 1995, 164(3):533-545.

15. Madara JL: Tight junction dynamics: is paracellular transport regulated? Cell 1988, 53(4):497-498.

16. Maeda S, Hsu LC, Liu H, Bankston LA, limura M, Kagnoff MF, Eckmann L, Karin M: Nod2 mutation in Crohn's disease potentiates NF-kappaB activity and IL-1beta processing. Science 2005, 307(5710):734-738.

17. Bras AM, Ketley JM: Transcellular translocation of Campylobacter jejuni across human polarised epithelial monolayers. FEMS Microbiol Lett 1999, 179(2):209-215

18. Walker RI, Schmauder-Chock EA, Parker JL, Burr D: Selective association and transport of Campylobacter jejuni through M cells of rabbit Peyer's patches. Can J Microbiol 1988, 34(10):1142-1147.

19. Burini JF, Gugi B, Merieau A, Guespin-Michel JF: Lipase and acidic phosphatase from the psychrotrophic bacterium Pseudomonas fluorescens: two enzymes whose synthesis is regulated by the growth temperature. FEMS Microbiol Lett 1994, 122(1-2):13-18.

20. Chantret I, Rodolosse A, Barbat A, Dussaulx E, Brot-Laroche E, Zweibaum A, Rousset M: Differential expression of sucrase-isomaltase in clones isolated from early and late passages of the cell line Caco-2: evidence for glucose-dependent negative regulation. J Cell Sci 1994, 107(Pt 1):213-225.

21. Lynch $T$, Livingstone $S$, Buenaventura $E$, Lutter $E$, Fedwick J, Buret AG, Graham D, DeVinney R: Vibrio parahaemolyticus disruption of epithelial cell tight junctions occurs independently of toxin production. Infect Immun 2005, 73(3):1275-1283.

22. Kubler I, Koslowski MJ, Gersemann M, Fellermann K, Beisner J, Becker S, Rothfuss K, Herrlinger KR, Stange EF, Wehkamp J: Influence of standard treatment on ileal and colonic antimicrobial defensin expression in active Crohn's disease. Aliment Pharmacol Ther 2009, 30(6):621-633.

23. Picot L, Mezghani-Abdelmoula S, Chevalier S, Merieau A, Lesouhaitier O, Guerillon J, Cazin L, Orange N, Feuilloley MG: Regulation of the cytotoxic effects of Pseudomonas fluorescens by growth temperature. Res Microbiol 2004, 155(1):39-46.

24. Picot L, Abdelmoula SM, Merieau A, Leroux P, Cazin L, Orange N, Feuilloley MG: Pseudomonas fluorescens as a potential pathogen: adherence to nerve cells. Microbes Infect 2001, 3(12):985-995.

25. Donnarumma G, Buommino E, Fusco A, Paoletti I, Auricchio L, Tufano MA: Effect of temperature on the shift of Pseudomonas fluorescens from an environmental microorganism to a potential human pathogen. Int J Immunopathol Pharmacol 23(1):227-234.

26. Vikstrom E, Tafazoli F, Magnusson KE: Pseudomonas aeruginosa quorum sensing molecule $\mathrm{N}$-(3 oxododecanoyl)-I-homoserine lactone disrupts epithelial barrier integrity of Caco-2 cells. FEBS Lett 2006, 580(30):6921-6928.

27. Dahan S, Dalmasso G, Imbert V, Peyron JF, Rampal P, Czerucka D: Saccharomyces boulardii interferes with enterohemorrhagic Escherichia coli-induced signaling pathways in T84 cells. Infect Immun 2003, 71(2):766-773.

28. Rossignol G, Sperandio D, Guerillon J, Duclairoir Poc C, Soum-Soutera E, Orange N, Feuilloley MG, Merieau A: Phenotypic variation in the Pseudomonas fluorescens clinical strain MFN1032. Res Microbiol 2009, 160(5):337-344.

29. Lepage $P$, Seksik $P$, Sutren $M$, de la Cochetiere MF, Jian $R$, Marteau $P$, Dore J: Biodiversity of the mucosa-associated microbiota is stable along the distal digestive tract in healthy individuals and patients with IBD. Inflamm Bowel Dis 2005, 11(5):473-480.

30. Kazmierczak Bl, Mostov K, Engel JN: Epithelial cell polarity alters RhoGTPase responses to Pseudomonas aeruginosa. Mol Biol Cell 2004, 15(2):411-419.

31. Schneeberger EE, Lynch RD: The tight junction: a multifunctional complex. Am J Physiol Cell Physiol 2004, 286(6):C1213-1228.

32. Frankel FR, Tucker RW, Bruce J, Stenberg R: Fibroblasts and macrophages of mice with the Chediak-Higashi-like syndrome have microtubules and actin cables. J Cell Biol 1978, 79(2 Pt 1):401-408.

33. Puthenedam M, Williams PH, Lakshmi BS, Balakrishnan A: Modulation of tight junction barrier function by outer membrane proteins of enteropathogenic Escherichia coli: role of F-actin and junctional adhesion molecule-1. Cell Biol Int 2007, 31(8):836-844.

34. Watson CJ, Hoare CJ, Garrod DR, Carlson GL, Warhurst G: Interferongamma selectively increases epithelial permeability to large molecules by activating different populations of paracellular pores. J Cell Sci 2005, 118(Pt 22):5221-5230.

35. Macutkiewicz C, Carlson G, Clark E, Dobrindt U, Roberts I, Warhurst G: Characterisation of Escherichia coli strains involved in transcytosis across gut epithelial cells exposed to metabolic and inflammatory stress. Microbes Infect 2008, 10(4):424-431.

36. Finlay BB, Falkow S: Salmonella interactions with polarized human intestinal Caco-2 epithelial cells. J Infect Dis 1990, 162(5):1096-1106.

37. Fleiszig SM, Zaidi TS, Fletcher EL, Preston MJ, Pier GB: Pseudomonas aeruginosa invades corneal epithelial cells during experimental infection. Infect Immun 1994, 62(8):3485-3493.

38. Mezghani-Abdelmoula S, Khemiri A, Lesouhaitier O, Chevalier S, Orange N, Cazin L, Feuilloley MG: Sequential activation of constitutive and inducible nitric oxide synthase (NOS) in rat cerebellar granule neurons by Pseudomonas fluorescens and invasive behaviour of the bacteria. Microbiol Res 2004, 159(4):355-363.

39. Kim SH, Wei Cl: Invasiveness and intracellular growth of multidrugresistant Salmonella and other pathogens in Caco-2 cells. J Food Sci 2007, 72(2):M72-78.

40. Baker NT, Graham LL: Campylobacter fetus translocation across Caco-2 cell monolayers. Microb Pathog 2010, 49(5):260-272.

doi:10.1186/1757-4749-2-16

Cite this article as: Madi et al:: Pseudomonas fluorescens alters epithelial permeability and translocates across Caco-2/TC7 intestinal cells. Gut Pathogens 2010 2:16. 